Farklı yüzey

işlemlerinin,

kobalt-krom (Co-Cr)

iskelet alt yapı ile

kaplama rezini veya

yapay diş arasındaki

bağlantı dayanımına etkisi

\section{Effect of different surface treatments on the bond strength between cobalt-chromium (Co-Cr) framework infrastructure and veneer resin or artificial tooth}

\section{Doç. Dr. Elif Aydoğan Ayaz}

Karadeniz Teknik Üniversitesi Diş Hekimliği Fakültesi, Protetik Diş Tedavisi A.D.,Trabzon

Orcid ID: 0000-0002-9577-5700

\section{Uzm. Dt. Seda Üstün}

Tekirdağ Ağız ve Diş Sağlığı Hastanesi,

Protetik Diş Tedavisi, Tekirdağ

Orcid ID: 0000-0002-6990-4660

\section{Geliş tarihi: 1 Ağustos 2020}

Kabul tarihi: 11 Mart 2021

doi: 10.5505/yeditepe.2022.98360

\section{Yazışma adresi:}

Uzm. Dt. Seda Üstün

Tekirdağ Ağız ve Diş Sağlığı Hastanesi,

Tekirdağ

Tel: 05070751789

E-posta: ustunseda@hotmail.com
ÖZET

Amaç: Çalışmanın amacı; metal primer, Nd:YAG lazer ve kumlama yüzey işlemlerinin, Co-Cr alaşım yüzeyi ile kaplama rezini ve akrilik yapay diş materyalleri arasındaki makaslama bağlantı dayanımına etkisini değerlendirmektir.

Gereç ve Yöntem: Çalışmada Co-Cr metal alaşımı (Magnum H60, İtalya), iki farklı kaplama rezini (Sinfony ve VisioCem, 3M ESPE, Almanya) ve iki farklı yapay diş (Acrylux, İtalya ve Ivoclar Vivadent AG, Liechtenstein) kullanıldı. 240 adet Co-Cr örnek Al2O3 ile kumlandı. Örnekler rezin ve yapay diş materyalleri için 4 gruba ve yüzey işlemleri için 6 alt gruba ayrıldı $(n=10)$. Grup 1'e yüzey işlem uygulanmadı (kontrol). Diğer gruplara ise farklı yüzey işlemleri uygulandı (Grup 2:metal primer, Grup 3:rocatec, Grup 4: Nd:YAG lazer, Grup 5: Nd:YAG lazer+rocatec ve Grup 6: Nd:YAG lazer+metal primer). 2 farklı yapay diş ve 2 farklı kaplama rezin ile bitim yapıldıktan sonra bağlantı dayanımı makaslama bağlantı testi ile değerlendirildi.

Bulgular: En yüksek bağlantı değerleri, lazer+rocatec gruplarında, en düşük değerler ise kontrol gruplarında görüldü. Farklı yüzey işlemleri ve farklı kaplama materyalleri, iskelet alt yapı ile rezin üst yapı bağlantısında etkili oldu $(P<.001)$. Yapay diş ve kaplama rezin grupları kendi aralarında bağlantı dayanımı açısından anlamlı farklılık göstermedi ( $P>0.05)$.

Sonuçlar: Metal yüzeyine farklı yüzey işlemleri uygulamak makaslama bağlantı değerlerini arttırmaktadır. Metal yüzeyine lazer ve lazerle birlikte rocatec veya metal primer uygulanması bağlantı dayanımını arttırmaktadır.

Anahtar kelimeler: Makaslama bağlantı dayanımı, Nd:YAG lazer, metal primer, kumlama.

\section{SUMMARY}

Aim: Purpose of the study; to evaluate the effect of metal primer, Nd: YAG laser and sandblasting surface treatments on shear bond strength between Co-Cr alloy surface and veneer resin and acrylic artificial teeth materials.

Material and Methods: In the study, Co-Cr metal alloy (Magnum H60, Italy), two different veneer resins (Sinfony and VisioCem, 3M ESPE, Germany) and two different artificial teeth (Acrylux, Italy and Ivoclar Vivadent, Liechtenstein) were used. 240 Co-Cr samples were sandblasted with Al2O3. Samples were divided into 4 groups for resin and artificial dental materials and 6 subgroups for surface treatments $(n=10)$. No surface treatment was applied to group 1 (control). Different surface treatments were applied to other groups (Group 2:metal primer, Group 3:rocatec, Group 4: Nd:YAG laser, Group 5: Nd:YAG laser+rocatec, Group 6: Nd:YAG laser+metal primer). After finishing with 2 different artificial teeth and 2 different veneer resins, the bond strength was evaluated with shear bond test. Results: The highest bonding values were seen in laser+rocatec groups and the lowest values in control groups. Different surface treatments and different veneer materials were effective on the bonding of the framework infrastructure and the resin superstructure $(P<.001)$. Artificial teeth and veneer resin groups didn't different significantly among themselves in ter- 
ms of bond strength $(P>0.05)$.

Conclusions: Applying different surface treatments on the metal surface increases the shear bonding values. Applying a laser to the metal surface and, rocatec or metal primer with the laser increases the bond strength.

Key words: Shear bond strength, Nd:YAG laser, alloy primer, sandblasting.

\section{GíRiş}

Hareketli parsiyel protezler, kısmen dişsiz bireylerin tedavisi amacıyla tasarlanır ${ }^{1}$ ve akrilik rezin ile kobalt-krom (CoCr) gibi metal alaşımların kombinasyonu şeklinde üretilir. ${ }^{2}$ Hareketli protezlerde iskelet üzerine uygulanan kaplama materyali ya da yapay diş materyalinin metal alt yapıdan ayrılması klinikte sık görülen hem protezin başarısını hem de hasta konforunu etkileyen önemli bir problemdir. Literatürler, yaklaşık \%25-35 oranında protezin, özellikle anterior bölgedeki yapay dişlerin alt yapıdan ayrılması ile tamir gerektirdiğini göstermektedir. ${ }^{3,4}$ Rezinin iskeletin metal yüzeyine zayıf bağlantısı veya rezin ile metal alaşımın termal genleşme katsayıları arasındaki fark gibi etkenlerle rezin ve metal altyapı birbirinden ayrılabilir. Bu durum rezinin renklenmesi, parçalanması veya ara yüz bağlantısının bozulması gibi istenmeyen sonuçlara yol açabilir. Rezin ve metal alaşım arasındaki boşluk artııça, tükürük ve diğer sıvıların boşluk içine mikro sızıntısı meydana gelir. Protezin patojenik mikroorganizmaları barındırma potansiyeli $\operatorname{artar}^{5,6}$

Rezin ile metal alt yapı arasında kuvvetli bir bağ oluşturmak için mekanik olarak retantif bir tasarım oluşturulabileceği gibi kimyasal olarak etkili adeziv sistemler de kullanılabilir. Mekanik retansiyon araçları; boncuk, iğne başı, ağ veya kafes şeklindeki tasarımları ve kumlamayı içerir.,8 Kumlama, bileme-pürüzleme, vertikal veya horizontal oluklar açma, lazer uygulama gibi birçok yöntem de bağlantı kuvvetini arttırmak için uygulanabilir. ${ }^{9,10}$ Livaditis ve Thompson"1, elektro-kimyasal ve kimyasal pürüzlendirme prosedürleri kullanarak rezin-metal alaşımlı sistemler için mikromekanik tutuculuk sağlanabileceğini bildirmiştir. Kimyasal içerikli metal-rezin bağlanma sistemlerinin tanıtılması bağlantıyı arttırmakta önemli bir gelişme olmuştur. ${ }^{12,13}$ Bu amaçla, 10-metakriloil oksidesil dihidrojen fosfat (MDP), metakriloiloksi alkil tiyofosforik asit (MEPS), metakriloksi etil trimellitik anhidrat (4-META) ve 10-metakriloiloksidekametilen malonik asit (MAC-10) gibi fosforik asit türevleri içeren metal primerlar kullanılabilir. ${ }^{14}$ Tanaka ve ark. ${ }^{15}$, 4-META içerikli preparatları geliştirmiş ve dental alaşımlara uygulandığında adezyona katkı sağladığını bildirmiştir. Yoshida ve ark. ${ }^{16}$ MEPS, MDP ve MAC-10 içeren primer uygulamasının rezin ve Co-Cr metal alaşımı arasındaki makaslama bağlantı dayanım kuvvetini arttırdığını rapor etmiştir. Bu yöntemlere ek olarak, alüminyum oksit partikülleriyle kumlama tekniği, protez yüzeyinde mikro boşluklar oluşturmak için kullanılmıştır. Kumlanmış alanın yüzey ölçümü, uygulama yapılmamış yüzeyden daha büyüktür. Bu durum, kumlama yapılmış yüzeylerin bağ kuvvetine katkı sağlamaktadır. ${ }^{17}$

Diş hekimliğinde carbon dioxide (CO2), Neodymium: Yttrium-Aliminum:Garnet (Nd:YAG), Erbium YAG (Er:YAG), Erbium,chromium: Yttrium: Scandium- Gallium- Garnet (Er,Cr:YSGG) gibi lazer tipleri kullanılmaktadır. Bu lazerler, sert ve yumuşak ağız dokularında uygulanabilirken, dental materyaller üzerinde de çeşitli amaçlarla kullanılmaktadır. ${ }^{17-18}$ Lazer sistemlerin diş hekimliğinde kullanılmasından sonra Murray ve ark. ${ }^{18}$, dental alaşıma lazer uygulamasının, alaşım ve rezin kompozit arasındaki bağ kuvvetini artırabildiğini bildirmiştir. Tugut ve ark.17, Er-YAG lazer uygulamasının bağlantı kuvvetini etkili bir şekilde arttırdığını rapor ederken, Er-YAG lazerin bağlantı kuvvetini değiştirmediğini bildiren çalışmalar da mevcuttur. ${ }^{19-21}$ Kim ve $\mathrm{Cho}^{22}$, Nd:YAG lazer uygulamasının, titanyum substratın porselen ile bağlanma kuvvetini arttırdığını ve bu yöntemin alüminyum oksit ile kumlama yöntemine alternatif olabileceğini bildirmiştir. Co-Cr alaşım yüzeylerinin kumlamayı takiben $46.9 \mathrm{~J} / \mathrm{cm} 2$ akış yoğunluğundaki Nd:YAG lazer ile pürüzlendirilmesi halinde, polimetil metakrilat ve Co-Cr arasındaki bağlantı kuvvetini arttırdığını bildirmiştir. ${ }^{23}$

Bu çalışmanın amacl; metal primer, Nd:YAG lazer ve kumlama işlemlerinin, Co-Cr alaşım yüzeyi ile iki farklı kaplama rezin materyali ve iki farklı akrilik yapay diş arasındaki makaslama bağlantı dayanım kuvvetlerini karşılaştırmalı olarak değerlendirmektir. Çalışmanın birinci hipotezi, farklı yüzey işlemlerinin, Co-Cr alaşım yüzeyi ile üst yapı materyalleri arasındaki bağlanma kuvvetini değiştirmeyeceğidir. Çalışmanın ikinci hipotezi; farklı üst yapı materyallerinin, Co-Cr alaşım yüzeyi ile arasında bağlanma dayanımında farklılık yoktur.

\section{GEREÇ VE YÖNTEM}

Çalışmada bir adet metal alaşımı (Co-Cr, Magnum H6O, MESA, Travagliato, Italya), iki farklı kaplama rezin materyali (Sinfony, 3M ESPE, Seefeld, Almanya ve VisioCem, 3M ESPE, Seefeld, Almanya) ve iki farklı akrilik yapay diş (Acrylux, Badia Polesine (Ro), Italya ve Ivoclar Vivadent AG, (Schaan, Liechtenstein) kullanıldı. Metal alaşım örneklerin yapımı için standart paslanmaz çelik kalıplar ile hazırlanan $2 \mathrm{~mm}$ kalınlıkta mum örnekler elde edildi. Toplam 240 adet standart mum örnek hazırlandı. Co-Cr örneklerin dökümü için fosfat bağlı revetman (Maruvest speed, Mega Dental GmbH, Almanya) kullanıldı. Üretici önerileri doğrultusunda döküm işlemleri gerçekleştirildi. Döküm sonrası tijler karbon separe ile kesildi. Revetman artıkları temizlendi ve yüzeyler taş frezle düzenlendi. Tüm örnekler $110 \mu \mathrm{m}$ Al2O3 ile 30 saniye süreyle kumlandı ve ultrasonik banyoda temizlendi. $2 \mathrm{~mm}$ kalınlık ve $6 \mathrm{~mm}$ uzunlukta hazırlanan metal örnekler, bağlantı yüzeyleri açıkta kalacak şekilde disk şekilli otopolimerizan akrilik rezin içerisine gömüldü 
(Resim1-2). Örnekler önce rastgele 4 gruba, ardından her bir yüzey işlemi için 6 gruba ayrıldı $(n=10)$. Bağlantı öncesi yüzey hazırlıkları aşağıdaki şekilde uygulandı. Gruplar ve yüzey işlemleri Tablo 1'de listelenmiştir.

Yüzey işlemlerinin ardından, iki farklı kaplama rezin materyali ile bitirilecek gruplarda öncelikle bir kat fırça ile opak rezin (Shofu Universal Opaque; Pre-Opaque, Shofu Dental $\mathrm{GmbH}$, Ratingen, Almanya), ardından $2 \mathrm{~mm}$ kalınlıkta kaplama rezin materyali uygulandı ve 20 saniye süreyle ışıkla polimerize edildi. İki farklı yapay diş ile bitirilecek gruplarda alt 1. molar akrilik rezin yapay diş kullanıldı. Yapay dişin alt bağlanma yüzeyleri düz olacak şekilde aşındırıldı, modelaj mumu ile metal örnek ve yapay diş sabitlendi. Örneklerin muflaya alınmasında ısı ile polimerize akrilik rezin (Meliodent, Kulzer GmbH, Hanau, Almanya) kullanıldı. Üretici firmanın önerdiği toz likit oranında karıştırılan akrilik rezin hamur kıvamına gelince mufla içindeki modelasyon boşluklarına yerleştirildi. Muflalar kapatılarak hidrolik preste sıkıldı, taşan fazlalık akrilik rezin uzaklaştırıdı ve 200 bar basınç altında 10 dakika bekletildi. Ardından muflalar brite alınarak su içinde kaynatımaya başlandı ve 30 dakika kaynatıldıktan sonra oda sıcaklığında soğumaya bırakıldı. Muflalardan çıkarılan örneklerdeki taşmış akrilik rezinler karbit frez yardımıyla temizlendi. Bağlantı testi öncesi tüm örnekler $37^{\circ} \mathrm{C}$ distile suda 24 saat bekletildi. Tüm işlemler tek bir hekim tarafından yapıldı.

Metal alt yapı ile kaplama rezini veya yapay diş ara yüzünde bağlantı kuvvetini değerlendirmek için makaslama bağlantı testi uygulandı. Bağlantı testi boyunca tüm örneklere $0.5 \mathrm{~mm} / \mathrm{dk}$ hızda kırılma gerçekleşene kadar kuvvet uygulandı (Llyod Instron Instruments, LRX, Fareham Hant, UK). Kırılma anındaki değerler Newton cinsinden elde edildi. Bu değerler yüzey alanına bölünerek (N/mm2) Megapaskal (MPa) birimine çevrildi ve kaydedildi.

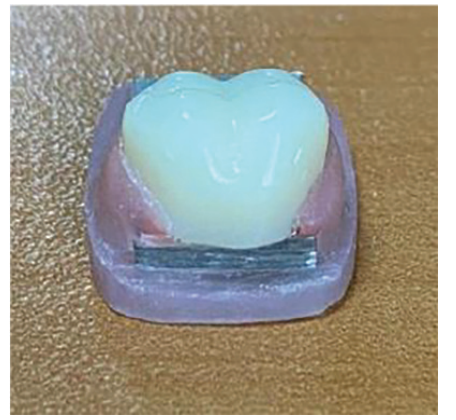

Resim 1. Metal alt yapıya bağlanan yapay diş

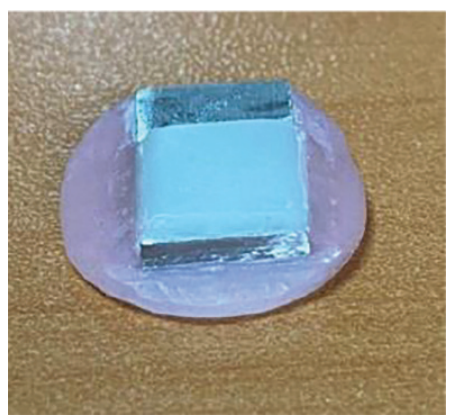

Resim 2. Metal alt yapıya bağlanan kaplama rezini
Tablo 1. Gruplar ve yüzey işlemleri.

\begin{tabular}{|c|c|}
\hline Gruplar & Yüzey işlemleri \\
\hline Grup 1: kontrol & Hiçbir yüzey işlemi uygulanmadi. \\
\hline Grup 2: metal primer & Metal primer (Alloy primer, Kuraray, New York, USA) \\
\hline Grup 3: rocatec & $30 \mu \mathrm{m}$ silisyum oksitle kapl1 $\mathrm{Al}_{2} \mathrm{O}_{3}$ Rocatec plus uygulamas \\
\hline Grup 4: lazer & Nd-Yag lazer $2 \mathrm{~kW} / 120 \mathrm{mj} / 50 \mathrm{~Hz} / 2 \mathrm{~mm}$ mesafeden \\
\hline Grup 5: lazer + rocatec & $\begin{array}{l}\text { Nd-Yag lazer } 2 \mathrm{~kW} / 120 \mathrm{mj} / 50 \mathrm{~Hz} / 2 \mathrm{~mm} \text { mesafeden }+30 \mu \mathrm{m} \\
\text { silisyum oksitle kaplı } \mathrm{Al}_{2} \mathrm{O}_{3} \text { Rocatec plus uygulamas }\end{array}$ \\
\hline Grup 6: lazer +metal primer & $\begin{array}{l}\text { Nd-Yag lazer } 2 \mathrm{Kw} / 120 \mathrm{mj} / 50 \mathrm{~Hz} / 2 \mathrm{~mm} \text { mesafeden }+ \\
\text { Metal primer (Alloy primer, Kuraray, New York, USA) }\end{array}$ \\
\hline
\end{tabular}

Çalışmada elde edilen bulguların istatistiksel analizi için; farklı yüzey işlemlerinin iskelet alt yapı ile kaplama materyallerinin bağlantısına etkisinin değerlendirilmesinde iki yönlü varyans analizi testi (ANOVA) uygulandı (SPSS version 12.0 for Windows; Chicago, IL). Gruplar arası çoklu karşılaştırmalar Bonferroni testi kullanılarak yapıldı. Sonuçlar \%95 güven aralığında ve $\mathrm{P}<0.05$ anlamlılık düzeyinde değerlendirildi.

\section{BULGULAR}

Gruplara ait ortalama bağlantı değerleri ve standart sapmalar Tablo 2'de görülmektedir.

Bu sonuçlara göre en yüksek bağlantı değerleri, tüm materyaller için, lazer+rocatec grubunda görülürken (Grup 5), en düşük değerler ise herhangi bir yüzey uygulaması yapılmayan kontrol gruplarında (Grup 1) görüldü.

İki yönlü varyans analizi testi sonuçlarına göre farklı yüzey işlemleri ve farklı kaplama materyallerinin iskelet alt yapı ile kaplama materyalleri arasındaki bağlantıda etkili olduğu bulundu $(P<.001)$. Farklı yüzey işlemleri ve kaplama materyalleri arasındaki etkileşimin anlamlı olduğu görüldü $(P<.001)$. Varyans analizine göre değişkenler arası etkileşim Tablo $3^{\prime}$ de görülmektedir.

Yüzey işlemleri tüm kaplama materyali gruplarında anlamlı farklılık gösterirken $(P<.001)$, yalnızca acrylux materyalinin kullanıldığı lazer (Grup 4) ve lazer+metal primer (Grup 6) grupları arasında anlamlı farklılık görülmedi ( $P>0.05)$. Yüzey uygulaması yapılmayan kontrol gruplarında, metal primer uygulanan (Grup 2) ve lazer+metal primer uygulanan (Grup 6) yapay diş materyali (acrylux ve vivodent) ve veneer rezin materyali (sinfony ve visiocem) grupları arasında anlamlı farklılık bulundu $(\mathrm{P}<.001)$. Yapay diş materyalleri ve kaplama rezin grupları kendi aralarında bağlantı dayanımı açısından anlamlı farklılık göstermedi $(P>0.05)$. 
Tablo 2. Makaslama bağlantı testi ortalama ve standart sapma değerleri (MPa). [Aynı satırdaki farklı büyük harfler gruplar arası farklılıkları ifade etmektedir. Ayn sütundaki farklı küçük harfler gruplar arası farklılıkları ifade etmektedir. $(P<0.05)]$

\begin{tabular}{|c|c|c|c|c|}
\hline & Acrylux & Vivadent & Sinfony & VisioCem \\
\hline $\begin{array}{l}\text { Grup } 1 \\
\text { Kontrol }\end{array}$ & $0,74( \pm 0,05)^{\mathrm{Aa}}$ & $0,77( \pm 0,06)^{\mathrm{Aa}}$ & $0,87( \pm 0,06)^{\mathrm{Ba}}$ & $0,88( \pm 0,06)^{\mathrm{Ba}}$ \\
\hline $\begin{array}{l}\text { Grup } 2 \\
\text { Metal Primer }\end{array}$ & $1,27( \pm 0,07)^{\mathbf{A b}}$ & $1,27( \pm 0,08)^{\mathbf{A b}}$ & $1,85( \pm 0,07)^{\mathbf{B b}}$ & $1,88( \pm 0,05)^{\mathbf{B b}}$ \\
\hline $\begin{array}{l}\text { Grup } 3 \\
\text { Rocatec }\end{array}$ & $2,81( \pm 0,10)^{\mathrm{Ac}}$ & $2,80( \pm 0,05)^{\mathrm{Ac}}$ & $2,84( \pm 0,08)^{\mathrm{Ac}}$ & $2,86( \pm 0,08)^{A c}$ \\
\hline $\begin{array}{l}\text { Grup } 4 \\
\text { Lazer }\end{array}$ & $4,28( \pm 0,14)^{A d}$ & $4,24 \pm(0,12)^{\mathbf{A d}}$ & $4,26( \pm 0,12)^{A d}$ & $4,33( \pm 0,10)^{A d}$ \\
\hline $\begin{array}{l}\text { Grup } 5 \\
\text { Lazer + Rocatec }\end{array}$ & $4,81( \pm 0,11)^{\mathrm{Ae}}$ & $4,79( \pm 0,10)^{\mathrm{Ae}}$ & $4,83( \pm 0,15)^{\mathrm{Ae}}$ & $4,83( \pm 0,14)^{\mathrm{Ae}}$ \\
\hline $\begin{array}{l}\text { Grup } 6 \\
\text { Lazer + Metal Primer }\end{array}$ & $4,25( \pm 0,05)^{\mathrm{Ad}}$ & $4,42( \pm 0,09)$ Af & $4,56( \pm 0,10)^{\mathrm{Bf}}$ & $4,52( \pm 0,15)^{\mathbf{B f}}$ \\
\hline
\end{tabular}

Tablo 3. İki yönlü Varyans analizi etkileşim tablosu $(* \mathrm{P}<0.05$ istatistiksel olarak anlamlı farklılık ifade eder).

\begin{tabular}{|l|l|l|l|l|}
\hline & Df & $\begin{array}{l}\text { Kareler } \\
\text { ortalaması }\end{array}$ & F & $P^{*}$ \\
\hline Kaplama materyalleri & 3 & 0,603 & 62,991 & $<.001$ \\
\hline Yüzey işlemleri & 5 & 109,918 & 11491,825 & $<.001$ \\
\hline $\begin{array}{l}\text { Kaplama materyali } \mathrm{x} \text { yüzey } \\
\text { işlemleri }\end{array}$ & 15 & 0,174 & 18,235 & $<.001$ \\
\hline
\end{tabular}

\section{TARTIŞMA}

Çalışmanın bulgularına göre, uygulanan yüzey işlemlerinin, farklı kaplama materyalleri ve akrilik yapay dişlerin Co-Cr iskelet alt yapıyla olan makaslama bağlantı dayanımını etkilediği görülmüş ve çalışmanın birinci hipotezi reddedilmiştir. Farklı kaplama materyalleri için uygulanan yüzey işlemleri değiştirildiğinde bağlantı dayanımı açısından farklılık oluştuğu görülmüştür. Bu nedenle çalışmanın ikinci hipotezi de reddedilmiştir.

Yapay dişlerin akrilik protezlere olan bağlantı kuvvetini arttırma girişimlerinin çoğu, akrilik dişin bağlantı yüzeyine uygulanan kimyasal işlemleri veya mekanik uygulamaları içerir. ${ }^{24}$ Uygulanan yüzey işlemleri, akrilik rezinlerin bileşenleri ve yapay dişlerin üretim aşamalarındaki farklılıklardan dolayı çalışmalar farklı sonuçlar vermektedir. ${ }^{25}$ Akrilik yapay dişlerin yapısı genel olarak PMMA'dan oluşmaktadır. Yapı içerisine çapraz bağ materyalleri, farklı mo- nomerler veya doldurucular eklenerek fiziksel özellikleri arttırılmaya çalışıımıştır. ${ }^{26}$ Çapraz bağlantı materyalleri genellikle akrilik yapıdaki materyallerin dayanıkııık, aşınma direnci, sertlik, eğilme dayanımı ve çatlamaya karşı direnç gibi özelliklerini arttırmak için kullanılırken, geleneksel akrilik yapay dişlerde bağlanma dayanımı değerlerinde azalmaya neden olmaktadır. ${ }^{27-29}$ Yüksek çapraz bağlantı ajanı varlığının yapay dişler ile kaide arasındaki bağlantıyı azalttığı bildirilmiştir. ${ }^{26,30}$ Bu nedenle dişlerin bağlantıyı sağlayacak kole bölgeleri, protez kaidesine olan bağlantıyı arttırmak için daha az çapraz bağlantı materyali içermelidir. ${ }^{31}$ Çalışmamızın bulgularına göre, akrilik yapay diş grupları, kaplama rezin ile bitirilen gruplara kıyasla daha düşük bağlantı değerleri göstermiştir. Bu durum, akrilik yapay diş yüzeylerinin çapraz bağlantı ajanları içermesinin metal yüzeyle olan bağlantısını da etkileyebileceğini düşündürmektedir. Ayrıca yapay dişin bağlantısında, monomerin genleşme sırasında yapı içerisine difüzyonu da rol oynamaktadır. Eğer polimer yüksek oranda çapraz bağ içeriyorsa, organik çözücüde genleşmesi de zorlaşmaktadir. ${ }^{32}$

Kimyasal bağlantı sağlanmasında primer içeriğindeki monomer önemli rol oynamaktadır. MDP içerikli primer kullanımı, rezin bazlı materyaller ile döküm Co-Cr alaşımlar arasındaki bağlantı kuvvetini arttırmaktadır. ${ }^{16,33}$ Bazı çalışmalarda, 6-metakriloiloksiheksil fosfonasetat (6-MHPA) içerikli primer solüsyonları ile kıyaslandığında MDP içerikli primer solüsyonların, döküm Co-Cr alaşımların bağlantısında daha etkili olduğu vurgulanmıştır. ${ }^{34,35}$ Söderholm ${ }^{36}$ rezin ile metal arasında kuvvetli bir bağ oluşturmak için metal yüzey kumlanarak hazırlanırken, yüzeye aynı zamanda fosfat bazıı bağlayıcı bir ajan uygulanması gerektiğini belirtmiștir. Bu önerilere paralel olarak, bizim çalışmamızda da primer uygulanmış örneklerin bağlantı değerlerinin, primer uygulanmamış kontrol grubu örneklerine ait değerlerden yüksek olduğu görülmektedir. Aynı zamanda lazer ile pürüzlendirme sonrasındaki primer uygulaması da sadece lazer ile pürüzlendirilen örneklerle kıyaslandığında bağlantı değerlerini artırmıştır.

Çalışmalarda, metal primerların metakriloil, dihidrojen fosfat ve desil parçaları içerdiği ve her bir parçanın ayrı bir işlevinin olduğu rapor edilmiştir. ${ }^{37,38}$ Dihidrojen fosfat kısmı, Co-Cr yüzeylerinin kumlanması ile oluşan metal oksitlere bağlanmakta ${ }^{37,38}$ ve böylece bağlantı kuvveti yükselmektedir. ${ }^{39,40} \mathrm{Bu}$ in vitro çalışmada kullanılan metal primer; aseton, 10-Metakriloiloksidesil dihidrojen fosfat (MDP) ve 6-(4-Vinilbenzil-N-propil) amino-1,3,5-triazin-2,4-dithione (VBATDT) gibi önemli bağlantı ajanlarını içermektedir.

Alüminyum oksit partikülleri ile aşındırma yüzey işlemi sonucunda, aşındırılmış rezinin serbest yüzey enerjisinin yükselmesi, abraze yüzey üzerinde düzensizlikler veya andırkatlar oluşması, mikromekanik retansiyonun ve buna bağıı olarak da makaslama bağlantı dayanımının artması 
beklenmektedir. ${ }^{41}$ Kim ve ark. ${ }^{42}$, dört farklı kaplama rezinin yüzey işlemleri sonrası Co-Cr metal yüzeylerine ve rezin yapay dişlere bağlantısını değerlendirmiştir. Tribokimyasal kumlama yapılmamış kaplama rezin grubunda adeziv başarısızlıklar daha yüksek iken, rocatec ve karboksil gruplarına sahip PMMA polimer (HLC-Bond) kullanılan kaplama rezinlerde başarısızlık daha çok koheziv olarak rapor edilmiştir. ${ }^{42}$ Rocatec uygulaması sırasında parçacıklar metal yüzeye çarptıklarında, parçacıkların kinetik enerjileri metal alaşımın erime noktası da olabilen termal enerjiye dönüşmektedir. Metal alaşımın erimesi 1-2 $\mu \mathrm{m}$ bir alan ile sınırlıdır. ${ }^{43,44} \mathrm{Bu}$ işlem sonucunda tribokimyasal etki ile metal yüzey alümina ve silika molekülleri ile kaplanmaktadır. ${ }^{45} \mathrm{Bu}$ in vitro çalışmanın bulgularına göre, tüm gruplarda en yüksek ortalama bağlanma değerleri lazer ve rocatec uygulanan yüzeylerde görülmüştür. Metal yüzeylere bağlanma kuvvetini arttırmak için, yüzeylere lazer ve rocatec uygulamasının birlikte kullanıması önerilebilir. Metal-rezin restorasyonlar, estetik ve kolay onarılabilir olmaları nedeniyle yaygın şekilde kullanılmaktadır. ${ }^{46}$ Multi-ünit protezler için, rezin kompozit kaplama materyalleri fırınlanan porselen materyallerine göre daha esnek olmaları, fırınlama büzülmesi olmayışı ve kullanımlarının kolay olması nedeniyle avantajlıdır. ${ }^{47}$ Çalışmamızda kaplama rezin materyallerinin Co-Cr alt yapılara olan bağlantısı, yapay dişlere göre daha yüksek bulunmuştur. Bu bulgu, kaplama rezinlerin ışık ile doğrudan polimerize edilebilmesi ve direkt uygulanmasının yüksek bağlantı değerlerine neden olabileceğini düşündürmektedir.

Sert doku veya yüzeylerde makroskobik ve mikroskobik düzensizliklerin oluşmasını sağlayarak yüzeyi bağlantı için hazırlamak amacıyla lazer uygulaması yapılabilir. ${ }^{48,49}$ Nd:YAG lazer, diş hekimliğinde feldspatik seramik yüzeylerini modifiye etmek ve titanyum-porselen bağlantısını geliştirmek amacıyla, intraoral yumuşak ve sert dokuların cerrahisinde ve endodontide kullanılmaktadır. ${ }^{18,50-52}$ Yılmaz ve ark. ${ }^{23}$, Nd:YAG lazer uygulamasının kumlanmış bağlantı yüzeyini pürüzlendirdiğini ve PMMA ile $\mathrm{Co}-\mathrm{Cr}$ alaşım arasındaki bağ gücünü arttırdığını bildirmiş, bu bağ kuvvetinin yüzeye metal primer uygulayarak daha da arttırılabileceğini rapor etmiştir. Çalışmamızın sonuçlarına bakıldığında, Nd:YAG lazer uygulaması ve silika kaplı alüminyum oksit partikülleri ile kumlamanın birlikte uygulandığı grupta, akrilik yapay diş veya kaplama rezin gruplarına ait bağlantı değerlerinin arttığı görülmektedir. Yüksek makaslama bağlantı değerleri; kumlanmış ve Nd:YAG lazer uygulanmış yüzeylerde PMMA taneciklerinin penetrasyonunun daha iyi olması ile açıklanabilir.

Bu çalışmanın limitasyonları in vitro şartların in vivo koşulları tam olarak yansıtamaması, klinik kullanımı simule eden termal yaşlandırma işleminin olmaması, materyallerin yaşlanmasına etki edecek yapay tükrük ve ağız içi ısı farklııklarının örnekler üzerine uygulanamamış olmasıdır.
Bu bilgiler doğrultusunda; protezlerin uzun dönem klinik başarısı için materyallerin birbirine olan bağlantısının sürekliliği kadar tamir yapılan durumlarda tamir işleminin etkinliğinin de önem taşıdığı görülmektedir. Çalışmamızın sonuçlarına göre lazerin tek başına veya diğer yüzey işlemleri ile kullanımının tamir sonrası bağlantı dayanımını arttırabileceği söylenebilir. Farklı tip lazer uygulamalarının, rezin ve metal içerikli protezlerin tamir başarısına etkisinin araştırıldığı çalışmaların çoğaltıımasının, literatürlere ve klinik başarıya katkı sağlayacağı düşünülmektedir.

\section{SONUÇLAR}

Çalışmamızın limitleri dahilinde elde edilen sonuçlar şu şekildedir:

1.Metal yüzeyine uygulanan farklı yüzey işlemleri, hiçbir uygulama yapılmadığı durumlara göre makaslama bağlantı değerlerini arttırmaktadır.

2.Metal yüzeyine tek başına lazer uygulanması ve lazerle birlikte rocatec veya metal primer uygulanması; kaplama materyali ile olan bağlantı dayanımını artırmaktadır.

\section{KAYNAKLAR}

1.Phoenix RD, Cagna DR, DeFreest CF. Stewart's Clinical Removable Partial Prosthodontics. 3th ed. Chicago: Quintessence Publishing; 2003. p. 1-18.

2.Wataha JC. Alloys for prosthodontic restorations. J Prosthet Dent 2002; 87: 351-363.

3.Vallittu PK, Lassila VP, Lappalainen R. Evaluation of damage to removable dentures in two cities in Finland. Acta Odontol Scand 1993; 51: 363-9.

4.Patil SB, Naveen BH, Patil NP. Bonding acrylic teeth to acrylic resin denture bases: A review. Gerodontology 2006; 23: 131-9.

5.Barclay CW, Spence D, Laird WRE, Marquis PM, Blunt L. Micromechanical versus chemical bonding between CoCr alloys and methacrylate resins. J. Biomed Mater Res B Appl Biomater 2007; 81: 351-357.

6.Creugers NHJ, Snoek PA, Van't Hof MA, Kayser AF. Clinical performance of resin-bonded bridges: a five year prospective study, Part III: Failure characteristics and survival after rebonding. J. Oral Rehabil 1990; 17: 179-186.

7.NaBadalung, DP, Powers JM. Effectiveness of adhesive systems for a Co-Cr removable partial denture. J Prosthodont 1998; 7: 17-25.

8.McConnell RJ. Metal-resin bonding. J Can Dent Assoc 1993; 21:38-42.

9.Korkmaz T, Doğan A, Doğan OM, Demir H. The bond strength of a highly cross-linked denture tooth to denture base polymers: A comparative study. J Adhes Dent 2011; 13: 85-92.

10.Geerts GA, Jooste $\mathrm{CH}$. A comparison of the bond strengths of microwave and water bath-cured denture material. J Prosthet Dent 1993; 70: 406-9.

11.Livaditis GJ, Thompson VP. Etched castings: An improved retentive mechanism for resin-bonded retainers. 
J Prosthet Dent 1982; 47: 52-8.

12.Mazurat RD, Pesun S. Resin-metal bonding systems: a review of the Silicoating and Kevloc systems. J Can Dent Assoc 1998; 64: 503-7.

13.Tam LE, McComb D. Shear bond strengths of resin luting cements to laboratory-made composite resin veneers. J Prosthet Dent 1991; 66: 314-21.

14.Leinfelder KF. Resin to metal bonding: overcoming esthetic problems. J Am Dent Assoc 1994; 125: 292-29.

15.Tanaka T, Nagata K, Takeyama M, Atsuta M, Nakabayashi $\mathrm{N}$ and et al. 4-META opaque resin-a new resin strongly adhesive to nickel-chromium. J Dent Res 1981; 60: 1667-1706.

16.Yoshida K, Taira Y, Sawase T, Atsuta M. Effects of adhesive primers on bond strength of self-curing resin to cobalt-chromium alloy. J Prosthet Dent 1997; 77: 617-620. 17.Tugut $F$, Akin $H$, Mutaf $B$, Akin GE, Ozdemir AK. Strength of the bond between a

silicone lining material and denture resin after Er: YAG laser treatments with different pulse durations and levels of energy. Lasers Med Sci 2012; 27: 281-5.

18.Murray AK, Attrill DC and Dickinson MR. The effects of $\mathrm{XeCl}$ laser etching of $\mathrm{Ni}-\mathrm{Cr}$ alloy on bond strengths to composite resin: a comparison with sandblasting procedures. Dent Mater 2005; 21: 538-544.

19.Akin $H$, Tugut $F$, Mutaf B, Akin G, Ozdemir AK. Effect of different surface treatments on tensile bond strength of silicone based soft denture liner. Lasers Med Sci 2011; 26: 783-8.

20.Akin $\mathrm{H}$, Tugut F, Guney $U$, Akar T. Shear bond strength of denture teeth to two chemically different denture base resins after various surface treatments. J Prosthodont 2014; 23: 152-6.

21.Malkoc MA, Demir N, Ogreten AT, Ozturk AN, Kilic HS. Effect of new laser type on shear bond strenght of acrylic teeth to denture base. J Rest Dent 2015; 3: 26-30.

22.Kim JT and Cho SA. The effects of laser etching on shear bond strength at the titanium ceramic interface. $J$ Prosthet Dent 2009; 101: 101-106.

23.Yilmaz A, Akyil MS, Hologlu B. The Effect of Metal Primer Application and Nd: YAG Laser Irradiation on the Shear-Bond Strength Between Polymethyl Methacrylate and Cobalt-Chromium Alloy. Photomed Laser Surg 2011; 29: 39-45.

24.Barbosa DB, Monteiro DR, Barão VA, Pero AC, Compagnoni MA. Effect of monomer treatment and polymerisation methods on the bond strength of resin teeth to denture base material. Gerodontology 2009; 26: 225-231. 25.Patil SB, Naveen BH, Patil NP. Bonding acrylic teeth to acrylic resin denture bases: a review. Gerodontology 2006; 23: 131-139.

26.Takahashi Y, Chai J, Takahashi T, Habu T. Bond strength of denture teeth to denture base resins. Int J Prostho- dont 2000; 13: 59-65.

27.Reis KR, Bonfante G, Pegoraro LF, Conti PC, Oliveira $\mathrm{PC}$, Kaizer $\mathrm{OB}$. In vitro wear resistance of three types of polymethyl methacrylate denture teeth. J Appl Oral Sci 2008; 16: 176-180.

28. Assuncao WG, Gomes EA, Barao VA, Barbosa DB, Delben JA, Tabata LF. Effect of storage in artificial saliva and thermal cycling on Knoop hardness of resin denture teeth. J Prosthodont Res 2010; 54: 123-127.

29.Vuorinen AM, Dyer SR, Lassila LV, Vallittu PK. Effect of rigid rod polymer filler on mechanical properties of polymethyl methacrylate denture base material. Dent Mater 2008; 24: 708-713.

30.Suzuki S, Sakoh M, Shiba A. Adhesive bonding of denture base resins to plastic denture teeth. J Biomed Mater Res 1990; 24: 1091-1103.

31.Loyaga-Rendon PG, Takahashi H, Hayakawa I, Iwasaki N. Compositional characteristics and hardness of acrylic and composite resin artificial teeth. J Prosthet Dent 2007; 98: 141-149.

32.Vallittu PK, Ruyter IE, Nat R. The swelling phenomenon of acrylic resin polymer teeth at the interface with denture base polymers. J Prosthet Dent 1997; 78: 194-199.

33. Kawaguchi T, Shimizu H, Lassila LVJ, Vallittu PK, Takahashi Y. Effect of surface preparation on the bond strength of heat-polymerized denture base resin to commercially pure titanium and cobalt-chromium alloy. Dent Mater J. 2011; 30: 143-50.

34. Matsuda $Y$, Yanagida $H$, Ide $T$, Matsumura $H$, Tanoue $\mathrm{N}$. Bond strength of poly(methyl methacrylate) denture base material to cast titanium and cobalt-chromium alloy. J Adhes Dent. 2010; 12: 223-9.

35.Sanohkan S, Urapepon S, Harnirattisai C, Sirisinha C, Sunintaboon P. Shear bond strength between autopolymerizing acrylic resin and Co-Cr alloy using different primers. Dent Mater J. 2012; 31: 765-71.

36.Söderholm KJM. The key for the indirect technique. In: Roulet JF and Degrange M, editors. Adhesion: The Silent Revolution in Dentistry. 1nd ed. Leipzig: Quintessence Publishing; 2000. p. 81-105.

37.Yanagida, $H$, Matsumura $H$, Taira $Y$, Atsuta $M$ and Shimoe S. Adhesive bonding of composite metal to cast titanium with varying surface preparation. $\mathrm{J}$ Oral Rehabil. 2002; 29: 121-126.

38.Yanagida $\mathrm{H}$, Matsumura $\mathrm{H}$ and Atsuta $\mathrm{M}$. Bonding of prosthetic composite material to Ti-6Al-7Nb alloy with eight metal conditioners and a surface modification technique. Am J Dent 2001; 14: 291-294.

39.Shimizu H, Kurtz KS, Tachii Y and Takahashi Y. Use of metal conditioners to improve bond strengths of autopolymerizing denture base resin to cast Ti-6Al-7 Nb and CoCr. J. Dent 2006; 34: 117-122.

40.Chikahiro O, Watanabe I, Hosoi T and Okabe T. Shear 
bond strengths of polymethyl methacrylate to cast titanium and cobalt-chromium frameworks using five metal primers. J Prosthet Dent 2000; 83: 50-57.

41.Barbosa DB, Monteiro DR, Barao VAR, Pero AC and Compagnoni MA. Effect of monomer treatment and polymerisation methods on the bond strength of resin teeth to denture base material. Gerodontology 2009; 26: 225-231. 42.Kim JY, Pfeiffer $P$, Niedermeier W. Effect of laboratory procedures and thermocycling on the shear bond strength of resin-metal bonding systems. J Prosthet Dent 2003; 90: 184-9.

43.Kourtis SG. Bond strengths of resin-to-metal bonding systems. J Prosthet Dent 1997; 78: 136-45

44.Tiller HJ, Magnus B, Goebel R, Musil R, Garshke A. The influence of sandblasting on metal alloy surface. Die Quintessenz 1985; 6: 1927-34, 2151-8.

45. Özcan M, Pfeiffer P, Nergiz I. A brief history and current status of metal and ceramic surface-conditioning concepts for resin bonding in dentistry. Quintess Int 1998; 29: 713-24.

46.Berge M. Properties of prosthetic resin-veneer materials processed in commercial laboratories. Dent Mater 1989; 5: 77-82.

47. Reich SM, Petschelt A, Wichmann M, Frankenberger R. Mechanical properties and three-body wear of veneering composites and their matrices. J Biomed Mater Res 2004; 69: 65-9.

48.Foxton RM, Cavalcanti AN, Nakajima M, Pilecki P, Sherriff $\mathrm{M}$ et al. Durability of resin cement bond to aluminium oxide and zirconia ceramics after air abrasion and laser treatment. J Prosthodont 2011; 20: 84-92.

49.Akyil MS, Uzun IH, Bayindir F. Bond strength of resin cement to yttrium-stabilized tetragonal zirconia ceramic treated with air abrasion, silica coating, and laser irradiation. Photomed Laser Surg 2010; 28: 801-8.

50.Coluzzi DJ. Fundamentals of dental lasers: science and instruments. Dent Clin North Am 2004; 48: 751-770.

51. Meire M, Mavridou A, Dewilde N, Hommez G and De Moor RJ. Longitudinal study on the influence of Nd:YAG laser irradiation on microleakage associated with two filling techniques. Photomed Laser Surg 2009; 27: 611-616. 52.Kim JT and Cho SA. The effects of laser etching on shear bond strength at the titanium ceramic interface. J Prosthet Dent 2009; 101: 101-106. 